IUCrJ

ISSN 2052-2525

PHYSICS|FELS

Received 20 July 2021

Accepted 3 November 2021

Edited by $\mathrm{H}$. Chapman, DESY/Universität Hamburg, Germany

\# Current address: Institute for Protein Research, Osaka University, 3-2 Yamadaoka, Suita, Osaka, 565-0871, Japan

$\S$ Current address: Institute of Multidisciplinary Research for Advanced Materials, Tohoku University, 2-1-1 Katahira, Aoba-ku, Sendai 980-8577, Japan

- Current address: Department of Biophysical Chemistry, School of Pharmaceutical Sciences, Wakayama Medical University, 25-1 Shichibancho, Wakayama 640-8156, Japan

Keywords: serial crystallography; SFX; protein structures; sample delivery; XFELs; LCP; lipidic mesophase; multi-drug exporters; $\mathrm{ABC}$ transporters; Cyanidioschyzon merolae; CmABCB1.

PDB reference: $\mathrm{CmABCB} 1$ in lipidic mesophase by LCP-SFX, 7fC9

Supporting information: this article has supporting information at www.iucrj.org
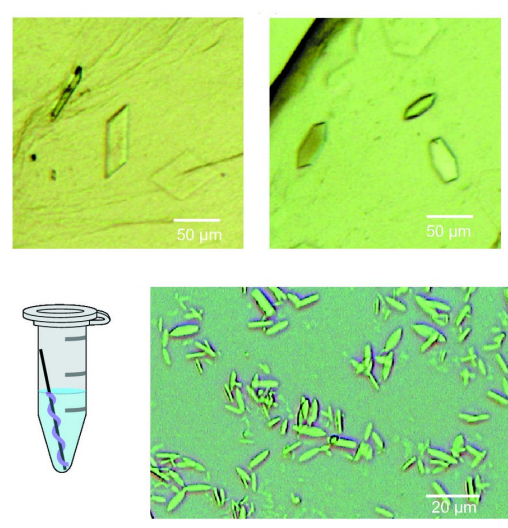

OPEN $\odot$ ACCESS

\section{Crystal structure of $\mathrm{CmABCB1}$ multi-drug exporter in lipidic mesophase revealed by LCP-SFX}

\author{
Dongqing Pan, ${ }^{\mathrm{a}}$ Ryo Oyama, ${ }^{\mathrm{a}}$ Tomomi Sato, ${ }^{\mathrm{a}}$ Takanori Nakane, ${ }^{\mathrm{b}} \neq$ Ryo Mizunuma, \\ Keita Matsuoka, ${ }^{\mathrm{a}}$ Yasumasa Joti, ${ }^{\mathrm{c}}$ Kensuke Tono, ${ }^{\mathrm{c}}$ Eriko Nango, ${ }^{\mathrm{d}} \S$ So Iwata, ${ }^{\mathrm{d}, \mathrm{e}}$ Toru \\ Nakatsu $^{\mathrm{a}, \mathrm{d}} \boldsymbol{\sigma}$ and Hiroaki Kato ${ }^{\mathrm{a}, \mathrm{d} *}$
}

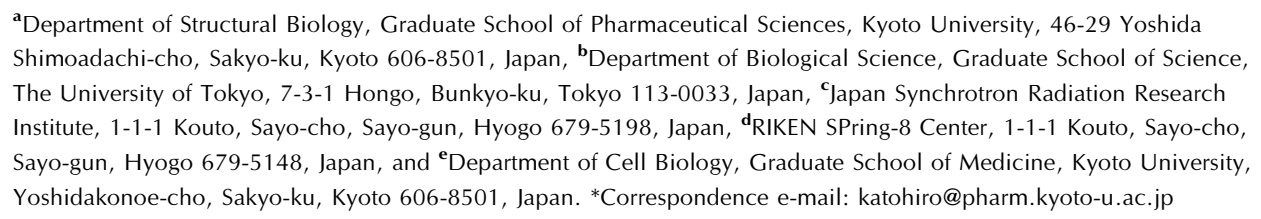

CmABCB1 is a Cyanidioschyzon merolae homolog of human ABCB1, a well known ATP-binding cassette (ABC) transporter responsible for multi-drug resistance in various cancers. Three-dimensional structures of ABCB1 homologs have revealed the snapshots of inward- and outward-facing states of the transporters in action. However, sufficient information to establish the sequential movements of the open-close cycles of the alternating-access model is still lacking. Serial femtosecond crystallography (SFX) using X-ray freeelectron lasers has proven its worth in determining novel structures and recording sequential conformational changes of proteins at room temperature, especially for medically important membrane proteins, but it has never been applied to $\mathrm{ABC}$ transporters. In this study, 7.7 monoacylglycerol with cholesterol as the host lipid was used and obtained well diffracting microcrystals of the $130 \mathrm{kDa}$ CmABCB1 dimer. Successful SFX experiments were performed by adjusting the viscosity of the crystal suspension of the sponge phase with hydroxypropyl methylcellulose and using the high-viscosity sample injector for data collection at the SACLA beamline. An outward-facing structure of CmABCB1 at a maximum resolution of $2.22 \AA$ is reported, determined by SFX experiments with crystals formed in the lipidic cubic phase (LCP-SFX), which has never been applied to ABC transporters. In the type I crystal, CmABCB1 dimers interact with adjacent molecules via not only the nucleotide-binding domains but also the transmembrane domains (TMDs); such an interaction was not observed in the previous type II crystal. Although most parts of the structure are similar to those in the previous type II structure, the substrate-exit region of the TMD adopts a different configuration in the type I structure. This difference between the two types of structures reflects the flexibility of the substrate-exit region of $\mathrm{CmABCB} 1$, which might be essential for the smooth release of various substrates from the transporter.

\section{Introduction}

ATP-binding cassette $(\mathrm{ABC})$ transporters, a large protein family with members in all organisms, mediate translocation of various substrates across membranes by coupling transport to ATP binding and hydrolysis (Rees et al., 2009; Thomas \& Tampé, 2020; Srikant \& Gaudet, 2019). Among the functionally characterized $\mathrm{ABC}$ transporters, multi-drug $\mathrm{ABC}$ exporters are responsible for multi-drug resistance (MDR) in various cancers and have been regarded as important protein targets in medical research (Borst \& Elferink, 2002; Robey et al., 2018). MDR in human cells is caused mainly by three ABC 
exporters, $\mathrm{ABCB} 1, \mathrm{ABCC} 1$ and $\mathrm{ABCG} 2$, which belong to different subfamilies (Robey et al., 2018). Three-dimensional structures of these transporters, elucidated by extensive X-ray crystallography and cryo-electron microscopy studies, have greatly improved our understanding of their transport mechanisms (Alam et al., 2019, 2018; Aller et al., 2009; Ward et al., 2013; Kim \& Chen, 2018; Taylor et al., 2017; Manolaridis et al., 2018; Johnson \& Chen, 2018, 2017). These transporters share a common architecture of two transmembrane domains (TMDs) consisting of movable transmembrane (TM) helices dynamically controlled by two nucleotide-binding domains (NBDs), which repeat cycles of binding and hydrolyzing ATP followed by release of ADP and Pi (Thomas \& Tampé, 2020; Srikant \& Gaudet, 2019). Human ABCB1 (also known as Pglycoprotein, MDR1) is typically expressed in barrier tissues and protects cells by exporting xenobiotic compounds (Ambudkar et al., 1999); however, it also exports major anticancer drugs in the same way. ABCB1 has been proposed to export substrates through an alternating-access mechanism, and this idea has been confirmed by the inward-facing (IF) and outward-facing (OF) structures of human ABCB1 (Alam et al., 2019; Kim \& Chen, 2018) and its homologs from mice (Alam et al., 2018; Aller et al., 2009; Ward et al., 2013), Caenorhabditis elegans (Jin et al., 2012), and Cyanidioschyzon merolae (Kodan et al., 2014, 2019). Although the available structures provide snapshots of representative states of the transport cycle, they do not provide enough information to understand the quick structural changes of $\mathrm{ABC}$ transporters and their sequential movements. Hence, further development of time-resolved methods is required.

Serial femtosecond crystallography (SFX) using extremely bright X-ray free-electron laser (XFEL) pulses has advanced greatly over the last decade (Chapman et al., 2011; Weierstall et al., 2014; Spence, 2017; Johansson et al., 2017; Mizohata et al., 2018). This approach enables unique X-ray diffraction experiments with damage-free data collection, allowing researchers to study the structures of proteins that are susceptible to radiation damage (Kern et al., 2012; Johansson et al., 2013; Hirata et al., 2014; Suga et al., 2015; Fukuda et al., 2016). Various experimental phasing methods have proven to be applicable to structural determination (Barends et al., 2014; Batyuk et al., 2016; Nakane, Hanashima et al., 2016; Nakane et al., 2015; Nass et al., 2016; Yamashita et al., 2015, 2017). The remarkable successes of time-resolved SFX (TR-SFX) made SFX an essential method for unveiling the sequential changes that occur in proteins when they are in action (Tenboer et al., 2014; Barends et al., 2015; Pande et al., 2016; Nango et al., 2016; Suga et al., 2017; Tosha et al., 2017; Shimada et al., 2017; Stagno et al., 2017). SFX experiments using lipidic cubic phase (LCP) microcrystals are called LCP-SFX; this method was used to solve the damage-free structure of a G-protein-coupled receptor (GPCR), human serotonin $5-\mathrm{HT}_{2 \mathrm{~B}}$ receptor (Liu et al., 2013). After the initial success of LCP-SFX, many novel structures of different GPCRs (Caffrey, 2015; Fenalti et al., 2015; Zhang et al., 2015; Zhang, Han et al., 2017; Zhang, Qiao et al., 2017; Zhang, Zhao et al., 2017; Kang et al., 2015) and a diacylglycerol kinase (Li et al., 2015) were determined using
LCP-SFX, but LCP-SFX is rarely applied to other classes of membrane proteins.

Membrane proteins' LCP crystals exhibit layered (type I) crystal packing that greatly improves X-ray diffraction, even with micrometre-sized crystals (Caffrey, 2015). LCP crystals form in a lipid-water mixture, usually with high viscosity; this favors SFX experiments by decreasing the amount of sample required. Ejecting viscous LCP crystals from specially designed high-viscosity sample injectors at a rate of $\sim 0.1 \mu \mathrm{lmin}^{-1}$ creates a straight stream across the XFEL beam (Weierstall et al., 2014; Martiel et al., 2019; Shimazu et al., 2019). The amount of crystal suspension required is $\sim 100$ times greater when a gas dynamic virtual nozzle injector is used for non-viscous samples (DePonte et al., 2008; Tono et al., 2015). To use a high-viscosity sample injector for non-viscous crystals, various viscous delivery media have been tested (Martiel et al., 2019; Nam, 2019). Mixing crystals with mineral oil grease (Sugahara et al., 2015), synthetic grease (Sugahara et al., 2016), Vaseline (Botha et al., 2015), agarose (Conrad et al., 2015), hyaluronic acid (Sugahara et al., 2016), hydroxyethyl cellulose (HEC) (Sugahara et al., 2017), nuclear-grade grease (Sugahara et al., 2017), carboxymethyl cellulose sodium salt (Kovácsová et al., 2017), pluronic F-127 (Kovácsová et al., 2017), poly(ethylene oxide) (Martin-Garcia et al., 2017) or polyacrylamide (Park et al., 2019) provides sufficient viscosity and enables data collection by SFX. Among these delivery media, polysaccharide-based hydrogels have the lowest scattering background (Conrad et al., 2015; Sugahara et al., 2016, 2017; Kovácsová et al., 2017).

In this study, we performed LCP-SFX experiments using LCP crystals of CmABCB1, the only ABCB1 homolog with high-resolution crystal structures available in both IF and OF conformations (Kodan et al., 2019, 2014). We generated well diffracting LCP crystals of CmABCB1 using a mixture of 7.7 monoacylglycerol (MAG) and cholesterol as the host lipid. We successfully collected LCP-SFX data using two different cellulosic thickening reagents, HEC and hydroxypropyl methylcellulose (HPMC), as the delivery media. The resultant crystal structure of $\mathrm{CmABCB} 1$ was in the OF conformation and differed at the substrate exit from the previously reported OF structure (Kodan et al., 2019), implying that the substrateexit region is flexible.

\section{Results}

\subsection{LCP crystals of CmABCB1}

To perform SFX experiments at the SPring-8 Angstrom Free Electron Laser (SACLA) beamline, we used modified crystallization conditions to prepare microcrystals of the type II crystal of the $\mathrm{CmABCB} 1^{\mathrm{VVV}}$ mutant, which carries three point mutations (G277V/A278V/A279V) and easily forms crystals of the IF structure (Kodan et al., 2014). We obtained microcrystals of $\mathrm{CmABCB} 1^{\mathrm{VVV}}$ with a size of $10-40 \mu \mathrm{m}$ by increasing the concentration of the precipitant PEG 2000 MME from 12 to $16 \%$. One hundred milligrams of $\mathrm{CmABCB} 1^{\mathrm{VVV}}$ was purified from Pichia pastoris cells cultured 
using a multi-cycle jar-fermentation method, crystallized in batch, and used for data collection at SACLA beamline BL3 (Ishikawa et al., 2012; Tono et al., 2013) with a liquid injector system (Tono et al., 2015). The microcrystals diffracted $7 \mathrm{keV}$ XFEL pulses up to a resolution of $5 \AA$. However, this was not sufficient for structural determination at atomic resolution, highlighting the limitations of type II membrane protein crystals for SFX experiments.

We then tried crystallizing CmABCB1 using the LCP method, which has enabled crystallization of many membrane proteins as well diffracting crystals exhibiting type I (layered) crystal packing (Caffrey, 2015). Even micrometre-sized LCP crystals often provide sufficient diffraction data for structural determination. In these experiments, we replaced CmABCB1 with the $\mathrm{CmABCB} 1^{\text {OTA }}$ mutant carrying two point mutations (Q147A/T381A), which formed type II crystals in both IF and OF conformations (Kodan et al., 2019). We prepared the LCP mixture using 9.9 $\mathrm{MAG}$ and a $\mathrm{CmABCB} 1^{\mathrm{QTA}}$ protein solution containing AMPPNP and $\mathrm{Mg}^{2+}$, and screened the crystallization condition with glass sandwich plates [Fig. 1(a)]. Rectangular and hexagonal plate crystals formed under two conditions containing 1,4-butanediol as the precipitant [Figs. $1(b)$ and $1(c)$ ]. We then screened salts and found that the hexagonal plate crystals grew to the largest size $(50 \mu \mathrm{m})$ when $0.2 \mathrm{M} \mathrm{NH}_{4} \mathrm{Cl}$ was added to the crystallization solution. The maximum X-ray diffraction of the hexagonal plate crystal reached $4 \AA$ at SPring- 8 beamline BL41XU, which encouraged us to conduct further optimization.

We obtained well diffracting LCP crystals when we changed the host lipid of LCP from 9.9 MAG to a mixture of 7.7 MAG and cholesterol. The LCP of 7.7 MAG consists of a thinner lipid bilayer and larger water channels than that of 9.9 MAG (Misquitta et al., 2004). When we performed screening using the mixture of 7.7 MAG and cholesterol $(9: 1 w / w \%)$ as the host lipid, we observed rectangular plate crystals under two conditions and leaf-shaped crystals under one zinc-containing condition [Fig. 1(d)]. After cycles of optimization, high-quality leaf-shaped crystals of $\mathrm{CmABCB} 1^{\mathrm{QTA}}$ were obtained and used for data collection at SPring-8 beamline BL41XU. A complete dataset of $2.7 \AA$ resolution was generated by merging diffraction data from 26 leaf-shaped crystals.

\subsection{LCP-SFX of CmABCB1}

To perform LCP-SFX with CmABCB1 ${ }^{\mathrm{QTA}}$ LCP crystals, we prepared leaf-shaped crystals using a batch method. LCP paste of $\mathrm{CmABCB} 1^{\mathrm{OTA}}$ and $7.7 \mathrm{MAG} /$ cholesterol was wrapped around a metal wire and soaked in precipitant solution containing 1,4-butanediol, Tris buffer, and zinc acetate at $20^{\circ} \mathrm{C}$ [Fig. 1(e)]. Microcrystals of 5-30 $\mu \mathrm{m}$ appeared at high density in three to five days when the concentration of 1,4-butandiol was $26-30 \%$ [Fig. 1(f)]. As a result of the high 1,4-butanediol concentration, the LCP transformed into an oil-like state known as the sponge phase (Caffrey, 2015). We tried several microcrystal delivery media reported previously (Sugahara et al., 2015; Nakane, Hanashima et al., 2016; Suga et al., 2017; Nango et al., 2016) to increase the viscosity of our LCP crystal suspension because we wanted to use a highviscosity cartridge-type (HVC) injector developed in the SACLA beamline (Shimazu et al., 2019). However, the synthetic grease and the monoolein LCP paste were not able (a)

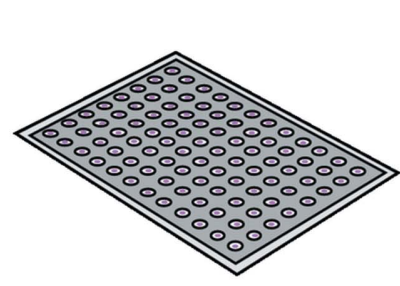

Sandwich plate

(d)

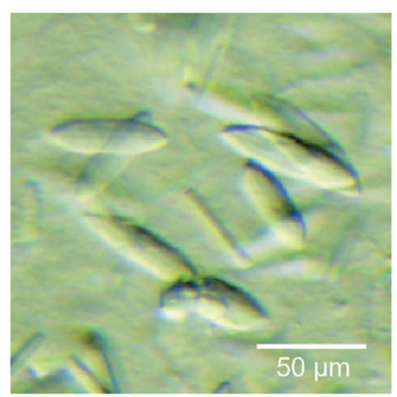

(b)

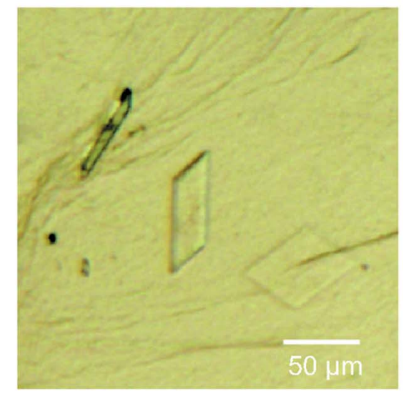

(e)

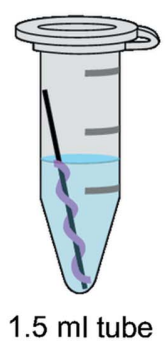

(f) (c)
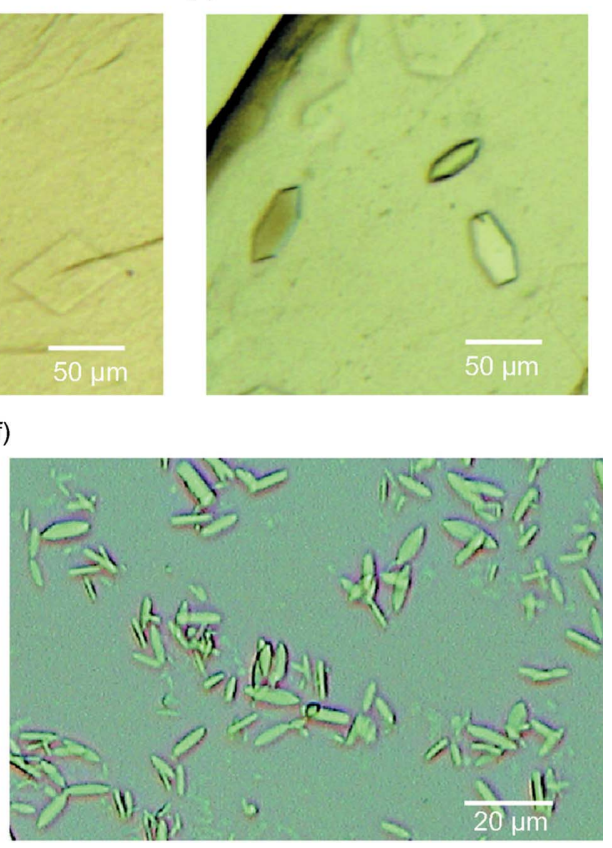

Figure 1

LCP crystals of CmABCB1. (a) A diagram of the 96-well glass sandwich plate used for LCP crystallization. (b) Rectangular plate crystals, (c) hexagonal plate crystals and $(d)$ leaf-shaped crystals of CmABCB1 $1^{\mathrm{OTA}}$ formed on the glass sandwich plate. $(e)$ A diagram depicting batch LCP crystallization of $\mathrm{CmABCB} 1$ in a $1.5 \mathrm{ml}$ tube. $(f)$ Microcrystals of $\mathrm{CmABCB} 1^{\mathrm{QTA}}$ formed using the batch method. 
to increase the viscosity of the sponge-phase crystal suspension of $\mathrm{CmABCB} 1^{\mathrm{QTA}}$ to a sufficient degree.

To find the substitute crystal carrier, we tested 23 different thickening reagents generally used as additives of foods, medicines and cosmetics (Table 1). Thickening reagents were mixed with water in different concentrations $(10-40 \%)$ and heated at $90^{\circ} \mathrm{C}$. Gelatin, polyacrylic acid 1000000 , HEC and HPMC formed homogeneous transparent gels with sufficient hardness at high concentration. Among these highly soluble reagents, HEC and HPMC were suitable for increasing the viscosity of the sponge-phase crystal suspension of $\mathrm{CmABCB} 1^{\mathrm{OTA}}$ when tested using the $\mathrm{HVC}$ injector. Straight streams of the mixtures of $\mathrm{CmABCB} 1^{\mathrm{OTA}}$ crystals and the carriers were stably formed.

Datasets of LCP-SFX of CmABCB1 ${ }^{\mathrm{QTA}}$ microcrystals were collected at SACLA beamline BL3. HEC and HPMC were dissolved in the crystallization solution of the CmABCB1 ${ }^{\text {QTA }}$ microcrystals at a concentration of $20-35 \%$. These transparent-gel carrier solutions were mixed with a CmABCB1 $1^{\text {QTA }}$ sponge-phase microcrystal suspension at a 1:1 ratio with the syringes and coupler usually used for LCP preparation. The resultant crystal mixture, containing $10-12.5 \%$ HEC or $12.5-$ $17.5 \%$ HPMC, was loaded onto the HVC injector and ejected at $0.4 \mu \mathrm{min}^{-1}$ to form a straight stream. Four diffraction datasets were collected using $30 \mathrm{~Hz}$ XFEL pulses for 70 $140 \mathrm{~min}$ for each condition (Table 2). We collected 122070 , 157812,183424 and 258430 images for the $10 \%$ HEC, $12.5 \%$ HEC, $12.5 \%$ HPMC and 17.5\% HPMC datasets, respectively. Comparison of the statistics of the $12.5 \%$ HEC and $12.5 \%$ HPMC datasets implied that HPMC was more suitable for data collection of CmABCB1 LCP microcrystals because both the hit rate and the number of indexed images were better. The statistics improved when we decreased the concentration of HEC to $10 \%$ or increased the concentration of HPMC to $17.5 \%$ (Table 2). The dataset with the highest resolution $(2.22 \AA$ ) was obtained using $17.5 \%$ HPMC as the carrier.

\subsection{LCP crystal structure of $\mathrm{CmABCB} 1$}

We analyzed the datasets of the $\mathrm{CmABCB} 1^{\mathrm{OTA}}$ crystals and determined the crystal structure of leaf-shaped LCP crystals of $\mathrm{CmABCB} 1^{\mathrm{QTA}}$ using the molecular replacement method. No significant difference was observed among the structures determined using the available datasets. Therefore, we performed the final refinement using the 17.5\% HPMC dataset, which had the highest resolution (Table 2).

In the crystal, $\mathrm{CmABCB} 1^{\mathrm{QTA}}$ forms homodimers in an $\mathrm{OF}$ conformation [Fig. 2(a)]. The asymmetric unit contains only one $\mathrm{CmABCB} 1^{\mathrm{QTA}}$ molecule. The two $\mathrm{CmABCB} 1^{\mathrm{OTA}}$ molecules forming a dimer are related to each other with twofold rotational symmetry. In this $\mathrm{OF} \mathrm{CmABCB} 1$ structure, two NBDs are attached to each other, sandwiching two AMPPNP: $\mathrm{Mg}^{2+}$ complexes between them. Twelve TM helices from both molecules formed a cup-shaped structure with an opening towards the opposite side of the NBD.

As expected, $\mathrm{CmABCB} 1^{\mathrm{QTA}}$ dimers packed in layers and formed type I crystals. The TMDs of the dimers were aligned in the same plane when adjacent molecules were displayed by
Table 1

Water solubility of 23 thickening agents.

S, soluble; IS, insoluble.

\begin{tabular}{|c|c|c|c|c|c|}
\hline & \multirow{2}{*}{ Thickening agents } & \multicolumn{4}{|c|}{ Concentration $(w / v \%)$} \\
\hline & & 10 & 20 & 30 & 40 \\
\hline 1 & Aluminium stearate, mono & IS & IS & IS & IS \\
\hline 2 & Amylopectin hydrate & IS & IS & IS & IS \\
\hline 3 & $\begin{array}{l}\text { Carboxymethyl cellulose, } \\
\quad \text { sodium salt }(n=\sim 1050)\end{array}$ & $\mathrm{S}$ & IS & IS & IS \\
\hline 4 & $\begin{array}{l}\text { Carboxymethyl cellulose, } \\
\quad \text { sodium salt }(n=\sim 500)\end{array}$ & S & IS & IS & IS \\
\hline 5 & Gelatin, from bovine bone & $\mathrm{S}$ & $\mathrm{S}$ & $\mathrm{S}$ & $\mathrm{S}$ \\
\hline 6 & Guar gum & IS & IS & IS & IS \\
\hline 7 & HEC & $\mathrm{S}$ & $\mathrm{S}$ & $\mathrm{S}$ & $\mathrm{S}$ \\
\hline 8 & $\begin{array}{l}\text { Hydroxypropyl cellulose } \\
1000-5000 \mathrm{cP} \\
\left(1 \mathrm{cP}=10^{-3} \mathrm{~Pa} \mathrm{~s}=1 \mathrm{mPa} \mathrm{s}\right)\end{array}$ & $\mathrm{S}$ & IS & IS & IS \\
\hline 9 & $\begin{array}{l}\text { Hydroxypropyl cellulose } \\
150-400 \mathrm{cP}\end{array}$ & $S$ & IS & IS & IS \\
\hline 10 & $\begin{array}{l}\text { Hydroxypropyl cellulose } \\
\quad 6.0-10.0\end{array}$ & S & IS & IS & IS \\
\hline 11 & HPMC & $\mathrm{S}$ & $\mathrm{S}$ & $\mathrm{S}$ & $\mathrm{S}$ \\
\hline 12 & Locust bean gum & $\mathrm{S}$ & $\mathrm{S}$ & $\mathrm{S}$ & $\mathrm{S}$ \\
\hline 13 & Methyl cellulose 400 & $\mathrm{~S}$ & IS & IS & IS \\
\hline 14 & Methyl cellulose 4000 & $\mathrm{~S}$ & IS & IS & IS \\
\hline 15 & Methyl cellulose 50 & $\mathrm{~S}$ & $\mathrm{~S}$ & $\mathrm{~S}$ & IS \\
\hline 16 & $\begin{array}{l}\text { Poly(vinyl alcohol) } 1000, \\
\text { completely hydrolyzed }\end{array}$ & $\mathrm{S}$ & $\mathrm{S}$ & $\mathrm{S}$ & $\mathrm{S}$ \\
\hline 17 & Polyacrylic acid 1000000 & $\mathrm{~S}$ & $\mathrm{~S}$ & $\mathrm{~S}$ & $\mathrm{~S}$ \\
\hline 18 & Polyacrylic acid 25000 & S & $\mathrm{S}$ & $\mathrm{S}$ & $\mathrm{S}$ \\
\hline 19 & Sodium alginate $500-600$ & $\mathrm{~S}$ & IS & IS & IS \\
\hline 20 & Sodium alginate $80-120$ & $\mathrm{~S}$ & IS & IS & IS \\
\hline 21 & Starch, soluble & $\mathrm{S}$ & $\mathrm{S}$ & $\mathrm{S}$ & IS \\
\hline 22 & Xanthan gum & IS & IS & IS & IS \\
\hline 23 & $\kappa$-Carrageenan & IS & IS & IS & IS \\
\hline
\end{tabular}

applying the symmetry operation [Fig. 2(a)], suggesting that the TMDs of CmABCB1 stayed in lipid bilayers of 7.7 MAG/ cholesterol in the crystal. Dimers next to each other were packed in an antiparallel orientation. Transmembrane helix 2 (TM2), TM4 and TM5 of one CmABCB1 molecule interacted with the same three helices of the adjacent molecule in an antiparallel orientation [Fig. 2(b)]. This interface of TMs contained many hydrophobic residues packed against each other in the lipid bilayer, whereas these hydrophobic residues were covered by detergent micelles in the type II crystal reported previously (Kodan et al., 2019). The hydrophilic regions of $\mathrm{Cm} A B C B 1$ dimers also interacted with each other via NBDs in the large aqueous space between the lipid bilayers. The distance between the lipid bilayers was $143 \AA$. A salt bridge between Arg559 and Glu446 and a zinc cluster containing three zinc ions interacting with three acidic residues (Asp551, Glu664 and Glu670) from two adjacent NBDs mediated the interactions between CmABCB1 dimers [Fig. 2(c)]. These head-to-head and tail-to-tail interactions determined the crystal packing and generated the well diffracting LCP crystals.

\subsection{Flexible nature of the substrate-exit region}

Structural alignment of the OF structure from this study with an OF structure from a previous report (Kodan et al., 2019) revealed the flexibility of the substrate-exit region of 
Table 2

Data-collection and refinement statistics.

Values in parentheses are for the highest-resolution shell.

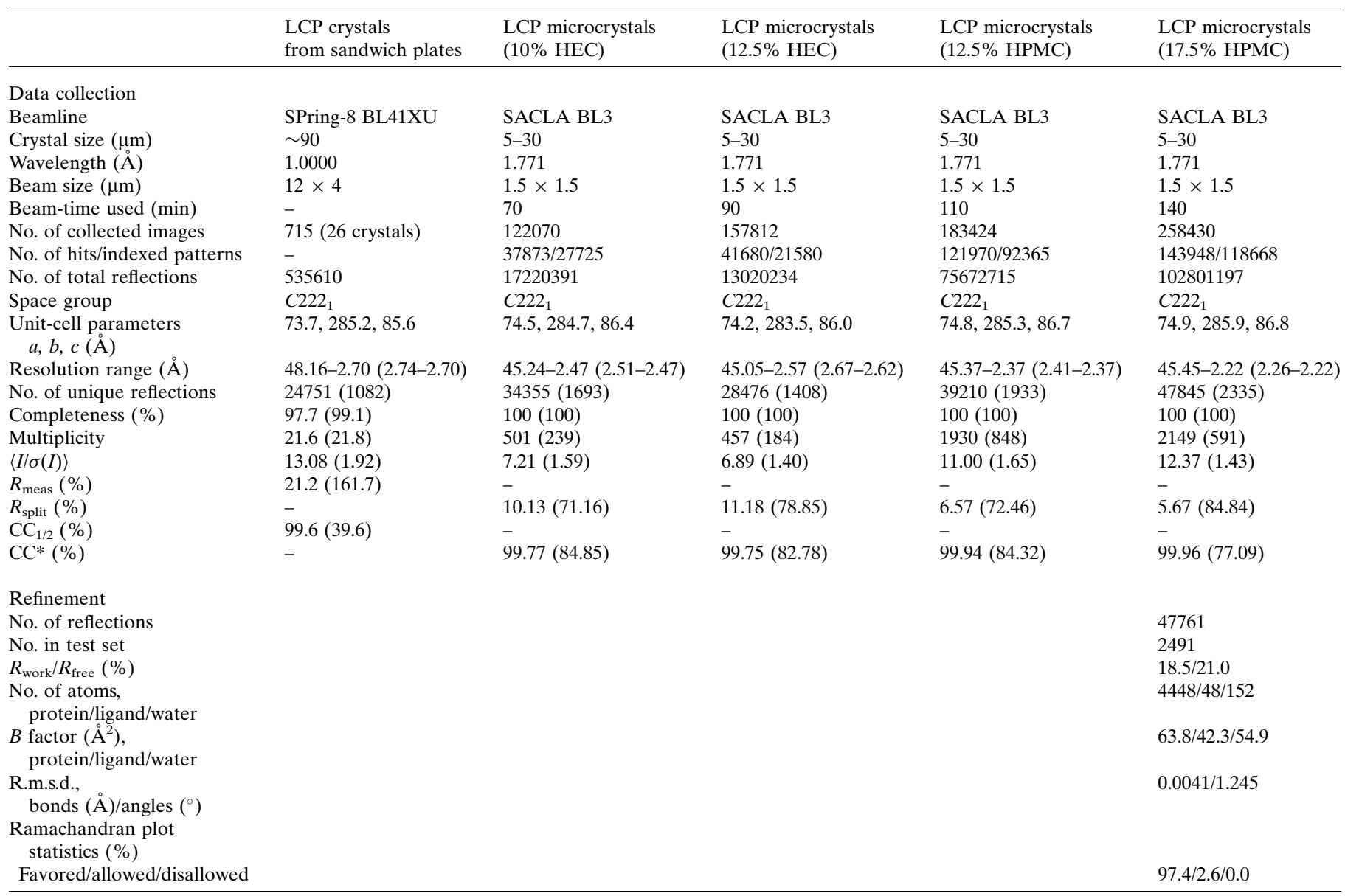

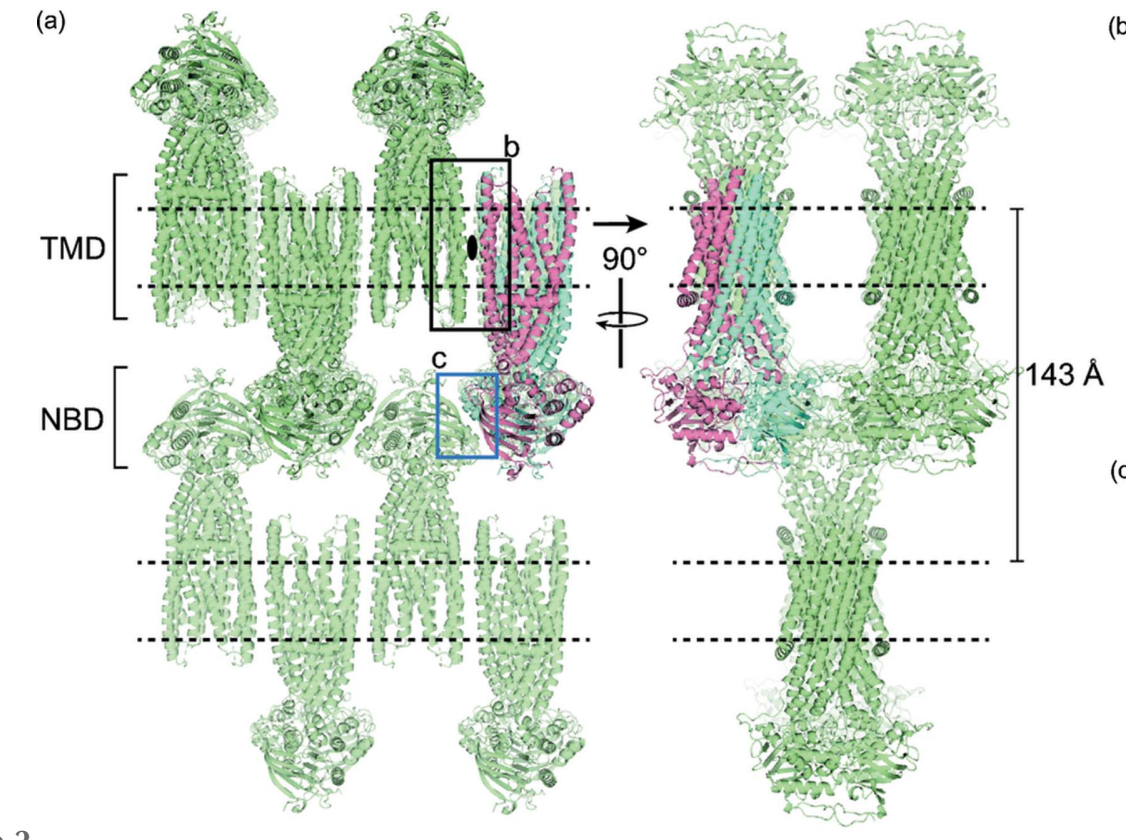

(b)

Figure 2

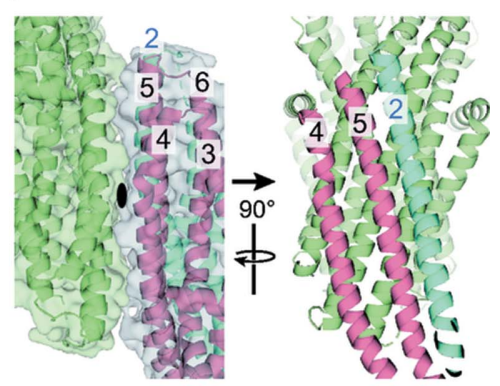

(c)

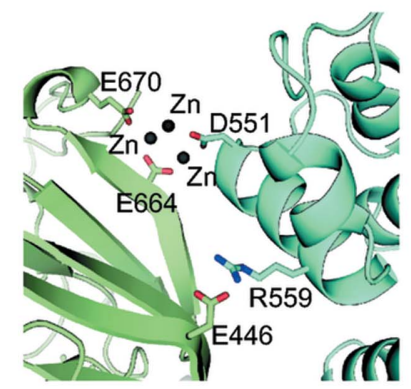

Type I crystal packing of the $\mathrm{CmABCB} 1^{\mathrm{QTA}}$ OF crystal structure. (a) Crystal packing of $\mathrm{CmABCBC1}{ }^{\text {QTA }}$ molecules shows alternating layers of antiparallel homodimers within the crystal. (b) An interface formed by the TM2, TM4 and TM5 helices of two CmABCB1 ${ }^{\text {QTA }}$ dimers. (c) Major interactions at the NBD interface. 
CmABCB1. In the two OF structures, two NBDs of CmABCB1 bound tightly to each other, assisted by the binding of the unhydrolyzable ATP analog, AMPPNP. This association of NBDs generated an overall conformational change through the TMD helices and opened the substrate exit at the extracellular site [Fig. 3(a)]. We observed little difference from the NBD region to the lower half of the TM region when we superimposed the two OF structures [Figs. $3(a)-3(c)]$. However, the upper half of the TM region exhibited significant differences [Figs. 3(a)-3(c)]. Parts of helices TM1, TM2, TM5 and TM6 constituting the substrate exit exhibited changes in orientation and 2-6 $\AA$ displacements [Figs. 3(a) and 3(b)]. The cleft of the substrate exit was slightly narrower in the type I structure but still showed a clear opening, as indicated by the sidechains of Phe384, an important residue that blocks substrate molecules when CmABCB1 is in an IF conformation (Kodan et al., 2019). These movements were caused by type I crystal packing in the lipid bilayer, in the sense that helices TM2, TM4 and TM5 from two adjacent molecules pushed against each other and became more vertical relative to the lipid bilayer [Figs. 2(b) and 3(a)]. TM1 and TM6 are connected to TM2 and TM5, respectively, by the extracellular loops, and their positions were consequently affected. In the previous type II structure, the substrate exit was surrounded by the detergent micelle and adopted a more opened conformation.

The $\mathrm{C}$-terminal helix in the previous structure became a $\beta$ strand in the new structure and formed a small $\beta$-sheet with the same $\beta$-strand of the other subunit [Fig. 3(a)]. One $\beta \mathrm{DM}$ molecule bound closely to the $\mathrm{C}$-terminal helix in the previous structure, which might have stabilized the helical conformation [Figs. 3(a) and 3(d)].

In the new structure, AMPPNP and $\mathrm{Mg}^{2+}$ bound at the same position of the nucleotide-binding pocket formed by the two NBDs [Figs. 3(a) and 3(d)]. The Walker A, Walker B and Qloop motifs also showed little difference between the two structures [Fig. 3(d)]. A zinc ion was found next to the $\gamma$ phosphate of the AMPPNP in the new structure, where it interacted with Glu610 and His643 [Fig. 3(d)].

\section{Discussion}

In this study, we performed an LCP-SFX experiment on the CmABCB1 multi-drug transporter and solved the type I (a)

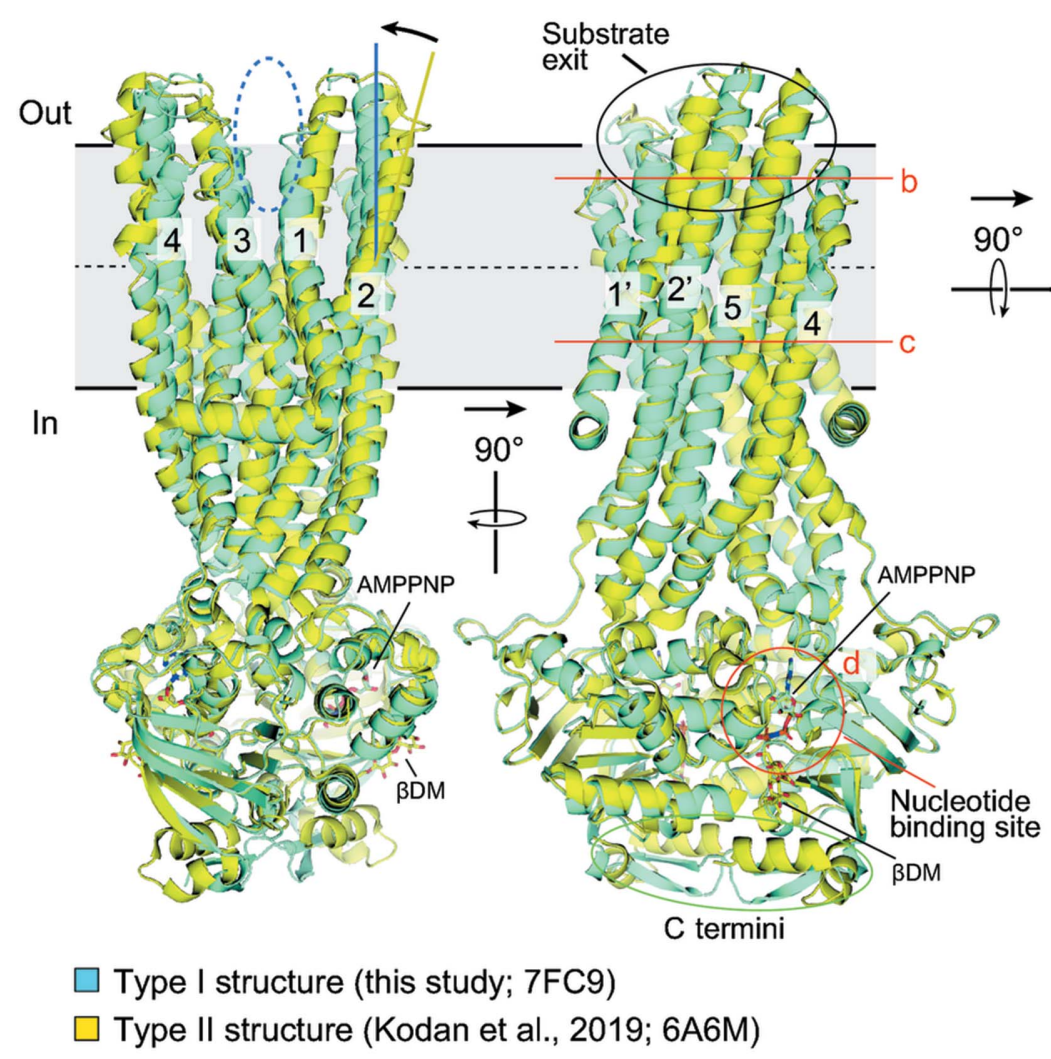

(b)

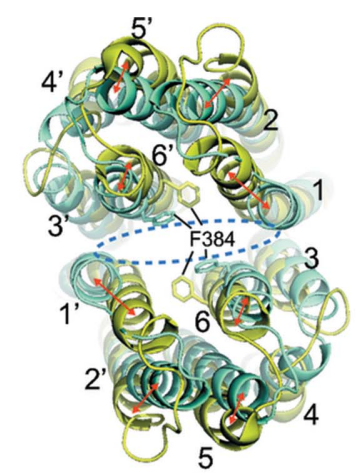

(c)

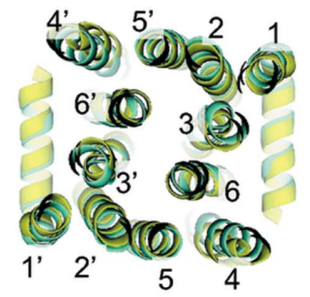

(d)

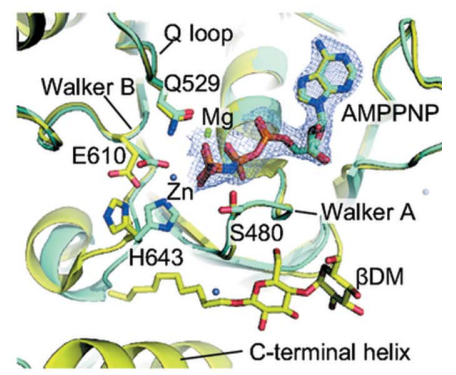

Figure 3

Structural comparison of the type I and type II OF crystal structures of CmABCB1 ${ }^{\mathrm{QTA}}$. (a) Structure alignment of the two types of crystal structures. Black solid lines indicate the boundaries of the lipid bilayer. Black dashed lines indicate the middle of the lipid bilayer. Red solid lines and a red ellipse indicate regions enlarged in $(b),(c)$, and $(d)$. Ellipses with blue dashed lines in $(a)$ and $(b)$ indicate the cleft of the substrate exit. $(b)$ Displacement of the TM helices at the outer leaflet region constituting the substrate exit. $(c)$ The inner leaflet part of the TM helices exhibits little difference. $(d)$ Nucleotidebinding sites of the two structures. The $\beta \mathrm{DM}$ molecule belongs to the type II structure and the $\mathrm{Zn}$ ion belongs to the type I structure. The blue mesh shows a $2 F_{\mathrm{o}}-F_{\mathrm{c}}$ electron-density map of AMPPNP in the type I structure, contoured at the $1.5 \sigma$ level. 
crystal structure in the OF conformation. This new structure confirmed the overall fold of the OF conformation reported previously (Kodan et al., 2019) and provided new insights about the flexibility of the substrate exit. CmABCB1 dimer transports diverse small-molecule substrates from the cytosol across the plasma membrane by coupling the energy of ATP hydrolysis to the repetition of IF and OF conformational changes (Kodan et al., 2019). This kind of alternating-access mechanism is shared by other $\mathrm{ABCB} 1$ homologs and $\mathrm{ABC}$ exporters (Thomas \& Tampé, 2020; Srikant \& Gaudet, 2019). Substrate molecules enter CmABCB1 from the cytosolic side of the IF conformation, are pushed upward to the substrate exit as NBDs associate and diffuse outward from the substrate exit when water molecules flow in. We hypothesize that the structural rigidity of $\mathrm{CmABCB} 1$ from the NBD to the lower part of the TM region and the flexibility of the substrate exit are both essential for the multi-drug export activity: the rigidity is required to transfer the conformational changes, whereas the flexibility is required to release the substrate. The flexible nature of the substrate-exit region was also observed in the OF structure of human ABCB1 (Kim \& Chen, 2018). In this structure, the extracellular regions that form the substrate exit exhibit less defined electron-microscopy density and higher $B$ factors relative to the rest of the structure (Kim \& Chen, 2018), which is consistent with our observations for CmABCB1.

The CmABCB1 LCP crystal is suitable for future TR-SFX studies. The OF conformation of CmABCB1 is in a highenergy state (Srikant \& Gaudet, 2019). The transporter will quickly return to the IF conformation as soon as ATP is hydrolyzed. If the hydrolysis can be induced in a controlled manner, we might be able to track the movement by coupling hydrolysis to the overall conformational change of the transporter. Good methods to induce ATP hydrolysis are essential to achieving this goal, and development of these techniques requires additional investigation.

LCP-SFX has been used to determine the structures of many GPCRs (Liu et al., 2013; Kang et al., 2015; Ishchenko et al., 2017; Johansson et al., 2019; Zhang, Han et al., 2017) and for analyzes of time-resolved structural changes (Nogly et al., 2018, 2016; Nango et al., 2016), but has never been applied to the study of $\mathrm{ABC}$ transporters, which usually possess large extramembrane regions including NBDs. This structural feature could be a disadvantage for LCP crystal formation. However, several studies have reported that protein complexes with large extramembrane regions could form LCP crystals (Rasmussen et al., 2011; Ishchenko et al., 2017; Asada et al., 2018). We successfully obtained LCP crystals of CmABCB1 using 9.9 MAG (monoolein) as the host lipid but the best crystals were obtained when we changed the host lipid to a $7.7 \mathrm{MAG} / \mathrm{cholesterol} \mathrm{mixture.} \mathrm{Crystals} \mathrm{formed} \mathrm{mainly}$ under conditions containing 1,4-butanediol, which induces the sponge phase (Caffrey, 2015). Our leaf-shaped crystals also formed in the oil-like sponge-phase solution. This supports the assumption that the sponge phase is preferable for type I crystal formation when using membrane proteins with large extramembrane regions (Caffrey, 2015).
Stable stream formation of CmABCB1 sponge-phase crystals at the SACLA beamline was achieved using the thickening reagents HEC and HPMC. HEC was previously used as the crystal carrier for SFX experiments on soluble protein crystals (Sugahara et al., 2017). One advantage of a cellulose-based delivery medium is the low background scattering (Nam, 2019). HEC and HPMC are both highly soluble and therefore very useful for improving viscosity when the crystal suspension cannot be easily concentrated by centrifugation. Mixing $20-25 \%$ HEC or $30-35 \%$ HPMC with equal volumes of sponge-phase crystal suspension produced an adequate paste for stable stream formation using the HVC injector (Shimazu et al., 2019) at the SACLA beamline. We obtained high-quality datasets using both HEC and HPMC; the HPMC datasets were slightly better than the HEC datasets in terms of maximum resolution. Although we need to perform further systematic evaluation of HPMC as a crystal carrier, we can conclude that HPMC is comparable with HEC for delivering microcrystals in SFX experiments and that HPMC was superior to HEC in the case of CmABCB1 LCP microcrystals.

\section{Materials and methods}

\subsection{Protein expression and purification}

$\mathrm{CmABCB} 1^{\mathrm{OTA}}$ was expressed in $P$. pastoris strain SMD1163. Plasmid pPICZA-CmABCB1(QTA)-FLAG-6His was generated by sub-cloning the coding sequence of CmABCB1 with a C-terminal FLAG-6His tag from pABC3CmABCB1-FLAG-His (Kodan et al., 2014) into pPICZA using the EcoRI and SalI sites (Thermo Fisher Scientific). The QTA mutation (Q147A/T381A) was introduced using primers reported previously (Kodan et al., 2019) by PCR-based sitedirected mutagenesis. The resultant open reading frame expresses the 696 amino acid CmABCB1 with an additional amino acid sequence, SGRDYKDDDDKHHHHHH, at the C terminus.

$P$. pastoris SMD1163 cells containing the integrated sequence pPICZA-CmABCB1(QTA)-FLAG-6His were cultured in a jar fermenter with a BIOFLO310 system (New Brunswick Scientific), and protein expression was induced by addition of methanol. We modified the fed-batch fermenter protocol of Kodan et al. (2014) to enable sequential culture by seeding the new culture with one tenth of the harvested cells. $P$. pastoris cells were cultured in 11 YPD medium in a baffled flask and grown at $30^{\circ} \mathrm{C}$ until the OD reached $5(600 \mathrm{~nm})$. The cells were separated from the medium by centrifugation and resuspended in 41 fermentation medium $\left[0.4 M \mathrm{KH}_{2} \mathrm{PO}_{4}\right.$, $2 \%(w / v)$ Bacto yeast extract, $4 \%(w / v)$ Bacto peptone, $2.68 \%(w / v)$ yeast nitrogen base without amino acids, $0.5 \%(w /$ v) sorbitol, $2 \%(w / v)$ hicasamino acids (Daigo), $0.3 \%(v / v)$ methanol, $4 \times 10^{-5} \%(w / v)$ biotin, $100 \mu \mathrm{g} \mathrm{ml}^{-1}$ zeocin, $100 \mu \mathrm{g} \mathrm{ml}^{-1}$ ampicillin sodium]. Temperature was maintained at $25^{\circ} \mathrm{C}$ and the concentration of dissolved oxygen was maintained at $40 \%$ air saturation. To optimize both cell growth and the expression of CmABCB1, methanol concentration was maintained at $0.3 \%$ by automatic control. After $48 \mathrm{~h}$ of culture, cells were harvested from 3.61 of medium, and 
the remaining 0.41 culture was combined with 3.61 of newly prepared fermentation medium for the second cycle of fermentation. This process could be repeated several times. Each harvest yielded $\sim 300 \mathrm{~g}$ of cells.

$\mathrm{CmABCB} 1^{\text {QTA }}$ was purified as previously described (Kodan et al., 2014) with minor modifications. The cell pellet $(300 \mathrm{~g})$ was suspended in lysis buffer [20 $\mathrm{m} M$ Tris- $\mathrm{HCl} \mathrm{pH}$ 7.0, $150 \mathrm{mM} \mathrm{NaCl}$, protease inhibitor cocktail (Roche)] to a volume of $750 \mathrm{ml}$ and disrupted with an EmulsiFlex homogenizer (Avestin). The cell debris was removed by centrifugation at $1500 \mathrm{~g}$ for $15 \mathrm{~min}$ and the membrane fraction was collected by centrifugation at $100000 \mathrm{~g}$ for $60 \mathrm{~min}$. Protein solubilization was performed by homogenizing the membrane with buffer containing $20 \mathrm{~m} M$ Tris- $\mathrm{HCl} \mathrm{pH} \mathrm{7.0,300} \mathrm{mM} \mathrm{NaCl}$, $20 \mathrm{~m} M$ imidazole, $1 \%(w / v)$ NIKKOL BL-9EX (Wako) and protease inhibitor cocktail (Roche), followed by incubation for $1 \mathrm{~h}$ at $4^{\circ} \mathrm{C}$. Insoluble material was removed by centrifugation at $100000 \mathrm{~g}$ for $60 \mathrm{~min}$. CmABCB1 ${ }^{\mathrm{OTA}}$ with the FLAG$6 \mathrm{His}$ tag was purified by $\mathrm{Ni}$-affinity chromatography with $\mathrm{Ni}$ IMAC resin (Bio-Rad) and eluted with elution buffer containing $20 \mathrm{~m} M$ Tris- $\mathrm{HCl} \mathrm{pH} 7.0,300 \mathrm{mM} \mathrm{NaCl}, 500 \mathrm{~m} M$ imidazole, and $0.2 \%(w / v) \quad n$-decyl- $\beta$-D-maltopyranoside ( $\beta \mathrm{DM}$; Anatrace). The protein solution was subjected to trypsin digestion with $5 \mu \mathrm{g}$ trypsin per $1 \mathrm{mg} \mathrm{CmABCB} 1\left(27^{\circ} \mathrm{C}\right.$, $30 \mathrm{~min}$ ) to remove the N-terminal 92 residues and the FLAG$6 \mathrm{His}$ tag of $\mathrm{CmABCB} 1$ as described previously (Kodan et al., 2014). The final step of size-exclusion chromatography (SEC) was performed using a HiLoad 16/600 Superdex $200 \mathrm{pg}$ column (GE Healthcare) with SEC buffer containing $20 \mathrm{mM}$ Tris- $\mathrm{HCl} \mathrm{pH}$ 7.0, $150 \mathrm{~m} M \mathrm{NaCl}$ and $0.2 \%(w / v) \beta \mathrm{DM}$. Peak fractions containing $\mathrm{CmABCB} 1^{\mathrm{OTA}}$ were concentrated to $30 \mathrm{mg} \mathrm{ml}^{-1}$. Approximately $6 \mathrm{mg}$ of $\mathrm{CmABCB} 1^{\text {QTA }}$ was obtained from 11 culture of fed-batch fermentation.

$\mathrm{CmABCB} 1^{\mathrm{VvV}}$ was expressed in $P$. pastoris strain SMD1163 and purified in the same manner as $\mathrm{CmABCB} 1^{\mathrm{OTA}}$. Plasmid pPICZA-CmABCB1(VVV)-6His was generated by sub-cloning the coding sequence of $\mathrm{CmABCB} 1$ with the $\mathrm{C}$ terminal 6His tag from pABC3-CmABCB1-FLAG-His (Kodan et al., 2014) into pPICZA. The VVV mutation (G277V/A278V/A279V) was introduced by PCR-based sitedirected mutagenesis as previously reported (Kodan et al., 2014). The resultant open reading frame expresses the 696 amino acid $\mathrm{CmABCB} 1$ with an additional amino acid sequence, VDHHHHHH, at the C terminus.

\subsection{Type II microcrystal production}

Protein solution containing $10 \mathrm{mg} \mathrm{ml}^{-1} \mathrm{CmABCB}^{\mathrm{VVv}}$ in SEC buffer was combined with crystallization solution containing 16\% PEG 2000 MME, $0.1 M$ magnesium nitrate and $0.1 \% \beta \mathrm{DM}$ at a volume ratio of $1: 1$. After gentle mixture and incubation at $10^{\circ} \mathrm{C}$ for $5 \mathrm{~h}$, microcrystals were grown to $10-40 \mu \mathrm{m}$.

\subsection{LCP crystallization and LCP microcrystal production}

LCP crystallization trials of $\mathrm{CmABCB} 1^{\mathrm{OTA}}$ were performed as previously described (Caffrey \& Cherezov, 2009). Twenty microlitres of protein solution of $\mathrm{CmABCB} 1^{\mathrm{QTA}}$ at $30 \mathrm{mg} \mathrm{ml}^{-1}$ was incubated for $1 \mathrm{~h}$ with $10 \mathrm{~m} M$ adenosine $5^{\prime}$ $(\beta, \gamma$-imido)triphosphate lithium salt hydrate (AMPPNP, Sigma) and $20 \mathrm{mM} \mathrm{MgCl}{ }_{2}$ at $20^{\circ} \mathrm{C}$. The protein samples were mixed with $30 \mu \mathrm{l}$ 1-oleoyl-rac-glycerol (monoolein or 9.9 MAG, Sigma) using $100 \mu \mathrm{l}$ gastight syringes (Hamilton). Fifty nanolitres of the mixture was dispensed onto each well of a 96-well glass sandwich plate (Hampton Research) and covered with $800 \mathrm{nl}$ of crystallization solution. For the initial screening, crystallization conditions were explored at $20^{\circ} \mathrm{C}$ using the Wizard Cubic LCP kit (Rigaku). Rectangular plate crystals were observed under condition \#26 (20\% 1,4butanediol, $0.1 M$ Tris- $\mathrm{HCl} \mathrm{pH}$ 8.5, $0.2 \mathrm{M} \mathrm{MgCl}_{2}$ ) and hexagonal plate crystals were observed under condition \#27 (20\% 1,4-butanediol, $0.1 \mathrm{M}$ citrate $\mathrm{pH} 5.5,0.2 \mathrm{M} \mathrm{NaCl}$ ). StockOptions Salt (Hampton Research) was used to explore the effects of 48 different salts. Addition of ammonium chloride yielded the best rectangular plate crystals with crystallization solution containing $25 \%$ 1,4-butanediol, $0.1 \mathrm{M}$ citrate $\mathrm{pH} 5.0$ and $0.2 \mathrm{M} \mathrm{NH}_{4} \mathrm{Cl}$. Crystals from this condition diffracted up to $4 \AA$ at SPring-8 synchrotron beamline BL41XU.

Leaf-shaped LCP crystals formed when a mixture of 1-(7Ztetradecenoyl)-rac glycerol (7.7 MAG, Avanti) and cholesterol (9:1 ratio) was used as the host lipid. To achieve complete solubilization of cholesterol in 7.7 MAG, the mixture of 7.7 MAG and cholesterol was sonicated in a Bioruptor UCD200 (Diagenode) until the mixture turned into a transparent solution. When we repeated the screen, solution \#25 from the Wizard Cubic LCP kit [20\% 1,4-butanediol, $0.1 M$ Tris-HCl $\mathrm{pH}$ 7.0, $0.2 \mathrm{M} \mathrm{Zn}(\mathrm{OAc})_{2}$ ] produced leaf-shaped crystals. Two other conditions (\#23 and \#81) yielded rectangular plate crystals. After optimization, the largest leaf-shaped crystal $(90 \mu \mathrm{m})$ formed in a crystallization solution containing $15 \%$ 1,4-butanediol, $0.1 \mathrm{M}$ Tris- $\mathrm{HCl} \mathrm{pH} 7.3$ and $0.2 \mathrm{M} \mathrm{Zn}(\mathrm{OAc})_{2}$.

Microcrystals of leaf-shaped $\mathrm{CmABCB} 1^{\mathrm{OTA}}$ crystal were generated by incubation of $50 \mu \mathrm{l}$ LCP containing $\mathrm{CmABCB} 1^{\text {OTA }}$ and 7.7 MAG/cholesterol as described above in a $1.5 \mathrm{ml}$ tube with $700 \mu \mathrm{l}$ of crystallization solution containing 26-30\% 1,4-butanediol, $0.1 M$ Tris $\mathrm{pH} 7.9$ and $0.2 \mathrm{M} \mathrm{Zn}(\mathrm{OAc})_{2}$. To facilitate LCP transfer and positioning in the tube, the LCP paste was wrapped around a steel wire when placed in the crystallization solution inside the tube. Microcrystals of 5-30 $\mu \mathrm{m}$ in length appeared after three to five days of incubation at $20^{\circ} \mathrm{C}$. The LCP crystals on the wire were transferred to a new tube and separated from the crystallization solution by holding the wire with tweezers. Some LCP crystals detached from the wire and were left floating on top of the crystallization solution. These crystals were collected using a micropipette.

\subsection{Data collection at synchrotron}

CmABCB1 ${ }^{\text {QTA }}$ LCP crystals were fished from the sandwich plates using MicroMeshes (MiTeGen) and were cryo-cooled with liquid nitrogen. All datasets of X-ray diffraction images were collected at SPring-8 beamline BL41XU (Hasegawa et al., 2013) using the helical data-collection method provided by 
the beamline's system. The amount of radiation damage was estimated using RADDOSE3D (Zeldin et al., 2013). A $460 \mu \mathrm{m}$ $\mathrm{Al}$ attenuator was used to collect diffraction images with average radiation damage of $<10 \mathrm{MGy}$. Diffraction patterns of a $15-50^{\circ}$ wedge were collected from each crystal at $100 \mathrm{~K}$ at a wavelength of $1.0000 \AA$. The exposure time was 1 s per frame and the oscillation range was $1^{\circ}$ per frame. Datasets of leafshaped LCP crystals were collected from 105 crystals. The best 26 datasets were chosen and merged for further analysis.

\subsection{LCP-SFX data collection at SACLA}

The LCP mixture of CmABCB1 ${ }^{\mathrm{OTA}}$, 7.7 MAG and cholesterol adopted an oil-like low-viscosity state after incubation with crystallization solution containing 1,4-butanediol. Microcrystals formed in the low-viscosity LCP mixture within three to five days. To increase the viscosity of the crystal suspension, we sought to identify suitable crystal carriers from among 23 different commercially available thickening agents (see Table S1 of the supporting information). Powders of these thickening agents were combined with water at various concentrations, heated at $90^{\circ} \mathrm{C}$ for $1 \mathrm{~h}$ and incubated at $25^{\circ} \mathrm{C}$ for one day. Air bubbles were removed by centrifugation. Four highly soluble thickening agents (HEC, HPMC, polyacrylic acid 1000000 , gelatin) were further evaluated for the ability to form a continuous stream using the HVC injector (Shimazu et al., 2019) at the SACLA beamline.

HEC and HPMC were able to support continuous streams and were therefore chosen for LCP-SFX experiments. HEC or HPMC was dissolved in the crystallization solution [26\% 1,4butanediol, $0.1 M$ Tris $\mathrm{pH}$ 7.9, 0.2 $\mathrm{M} \mathrm{Zn(OAc})_{2}$ ] at concentrations ranging from 20 to $35 \%$. These paste-like solutions were combined at 1:1 ratio with CmABCB1 ${ }^{\text {QTA }}$ LCP crystals using two syringes and a coupler as described previously (Conrad et al., 2015). The viscosity-adjusted crystal suspension was placed in the HVC injector, and SFX experiments were performed at SACLA beamline BL3 (Ishikawa et al., 2012; Tono et al., 2013). A continuous stream of crystal suspension was created at a flow rate of $0.4 \mu \mathrm{min}^{-1}$. Diffraction images were collected at $25^{\circ} \mathrm{C}$ with XFEL pulses of $30 \mathrm{~Hz}$ at $7.0 \mathrm{keV}$. The beam size was adjusted to $1.5 \times 1.5 \mu \mathrm{m}$. Diffraction patterns were recorded using a multiport $\mathrm{CCD}$ detector with eight sensor modules (Kameshima et al., 2014) at a sample-todetector distance of $50 \mathrm{~mm}$. The statistics of data collection are summarized in Table 2. Raw XFEL diffraction images for this article have been deposited in the Coherent X-ray Imaging Data Bank (CXIDB) (ID 193).

\subsection{Data reduction and structure determination}

LCP-SFX data collection was monitored using the on-thefly data-processing pipeline for SFX at SACLA (Nakane, Joti et al., 2016). Crystal hits were identified by Cheetah (Barty et al., 2014) and processed with CrystFEL 0.9.0 (White et al., 2012). Diffraction spots were located by the peakfinder 8 algorithm and indexed with XGANDALF (Gevorkov et al., 2019). Integrated intensities were merged by partialator in the CrystFEL suite with scaling but without partiality corrections.
Synchrotron diffraction data were processed using $X D S$ (Kabsch, 2010).

The initial phases were determined by molecular replacement using Phaser (McCoy et al., 2007). The crystal structure of the CmABCB1 outward-open form (PDB entry 6a6m; Kodan et al., 2019) was used as the search model. Structure building and refinement were performed with Coot (Casañal et al., 2020) and REFMAC5 (Kovalevskiy et al., 2018). Data collection and processing information are summarized in Table 2. PyMOL was used to make figures.

\section{Acknowledgements}

We thank Atsushi Kodan and Tomohiro Yamaguchi for technical support and advice for purification and crystallization of CmABCB1. We also thank the beamline staff at SACLA BL3 and SPring-8 BL41XU for technical assistance with data collection. The XFEL experiments were carried out at BL3 at SACLA with the approval of the Japan Synchrotron Radiation Research Institute (JASRI) (proposal Nos. 2015B8042 and 2016A8047). The data-collection experiments at SPring-8 BL41XU were carried out with the approval of JASRI proposal No. 2016A2503.

\section{Funding information}

This work was supported by the X-ray Free-Electron Laser Priority Strategy Program (MEXT) and JSPS KAKENHI [grant Nos. 19H05781 (EN), 20K15747 (DP), 20H03222 (DP and HK), 18H05269 (TN), 19H05780 (TN) and 19H05776 (SI)].

\section{References}

Alam, A., Kowal, J., Broude, E., Roninson, I. \& Locher, K. P. (2019). Science, 363, 753-756.

Alam, A., Küng, R., Kowal, J., McLeod, R. A., Tremp, N., Broude, E. V., Roninson, I. B., Stahlberg, H. \& Locher, K. P. (2018). Proc. Natl Acad. Sci. USA, 115, E1973-E1982.

Aller, S. G., Yu, J., Ward, A., Weng, Y., Chittaboina, S., Zhuo, R., Harrell, P. M., Trinh, Y. T., Zhang, Q., Urbatsch, I. L. \& Chang, G. (2009). Science, 323, 1718-1722.

Ambudkar, S. V., Dey, S., Hrycyna, C. A., Ramachandra, M., Pastan, I. \& Gottesman, M. M. (1999). Annu. Rev. Pharmacol. Toxicol. 39, 361-398.

Asada, H., Horita, S., Hirata, K., Shiroishi, M., Shiimura, Y., Iwanari, H., Hamakubo, T., Shimamura, T., Nomura, N., Kusano-Arai, O., Uemura, T., Suno, C., Kobayashi, T. \& Iwata, S. (2018). Nat. Struct. Mol. Biol. 25, 570-576.

Barends, T. R. M., Foucar, L., Ardevol, A., Nass, K., Aquila, A., Botha, S., Doak, R. B., Falahati, K., Hartmann, E., Hilpert, M., Heinz, M., Hoffmann, M. C., Köfinger, J., Koglin, J. E., Kovacsova, G., Liang, M., Milathianaki, D., Lemke, H. T., Reinstein, J., Roome, C. M., Shoeman, R. L., Williams, G. J., Burghardt, I., Hummer, G., Boutet, S. \& Schlichting, I. (2015). Science, 350, 445-450.

Barends, T. R. M., Foucar, L., Botha, S., Doak, R. B., Shoeman, R. L., Nass, K., Koglin, J. E., Williams, G. J., Boutet, S., Messerschmidt, M. \& Schlichting, I. (2014). Nature, 505, 244-247.

Barty, A., Kirian, R. A., Maia, F. R. N. C., Hantke, M., Yoon, C. H., White, T. A. \& Chapman, H. (2014). J. Appl. Cryst. 47, 1118-1131. Batyuk, A., Galli, L., Ishchenko, A., Han, G. W., Gati, C., Popov, P. A., Lee, M. Y., Stauch, B., White, T. A., Barty, A., Aquila, A., Hunter, M. S., Liang, M., Boutet, S., Pu, M., Liu, Z.-jie, Nelson, G., James, 
D., Li, C., Zhao, Y., Spence, J. C. H., Liu, W., Fromme, P., Katritch, V., Weierstall, U., Stevens, R. C. \& Cherezov, V. (2016). Sci. Adv. 2, e1600292.

Borst, P. \& Elferink, R. O. (2002). Annu. Rev. Biochem. 71, 537-592. Botha, S., Nass, K., Barends, T. R. M., Kabsch, W., Latz, B., Dworkowski, F., Foucar, L., Panepucci, E., Wang, M., Shoeman, R. L., Schlichting, I. \& Doak, R. B. (2015). Acta Cryst. D71, 387-397. Caffrey, M. (2015). Acta Cryst. F71, 3-18.

Caffrey, M. \& Cherezov, V. (2009). Nat. Protoc. 4, 706-731.

Casañal, A., Lohkamp, B. \& Emsley, P. (2020). Protein Sci. 29, 1069-1078.

Chapman, H. N., Fromme, P., Barty, A., White, T. A., Kirian, R. A., Aquila, A., Hunter, M. S., Schulz, J., DePonte, D. P., Weierstall, U., Doak, R. B., Maia, F. R. N. C., Martin, A. V., Schlichting, I., Lomb, L., Coppola, N., Shoeman, R. L., Epp, S. W., Hartmann, R., Rolles, D., Rudenko, A., Foucar, L., Kimmel, N., Weidenspointner, G., Holl, P., Liang, M., Barthelmess, M., Caleman, C., Boutet, S., Bogan, M. J., Krzywinski, J., Bostedt, C., Bajt, S., Gumprecht, L., Rudek, B., Erk, B., Schmidt, C., Hömke, A., Reich, C., Pietschner, D., Strüder, L., Hauser, G., Gorke, H., Ullrich, J., Herrmann, S., Schaller, G., Schopper, F., Soltau, H., Kühnel, K. U., Messerschmidt, M., Bozek, J. D., Hau-Riege, S. P., Frank, M., Hampton, C. Y., Sierra, R. G., Starodub, D., Williams, G. J., Hajdu, J., Timneanu, N., Seibert, M. M., Andreasson, J., Rocker, A., Jönsson, O., Svenda, M., Stern, S., Nass, K., Andritschke, R., Schröter, C. D., Krasniqi, F., Bott, M., Schmidt, K. E., Wang, X., Grotjohann, I., Holton, J. M., Barends, T. R. M., Neutze, R., Marchesini, S., Fromme, R., Schorb, S., Rupp, D., Adolph, M., Gorkhover, T., Andersson, I., Hirsemann, H., Potdevin, G., Graafsma, H., Nilsson, B. \& Spence, J. C. H. (2011). Nature, 470, 73-77.

Conrad, C. E., Basu, S., James, D., Wang, D., Schaffer, A., RoyChowdhury, S., Zatsepin, N. A., Aquila, A., Coe, J., Gati, C., Hunter, M. S., Koglin, J. E., Kupitz, C., Nelson, G., Subramanian, G., White, T. A., Zhao, Y., Zook, J., Boutet, S., Cherezov, V., Spence, J. C. H., Fromme, R., Weierstall, U. \& Fromme, P. (2015). IUCrJ, 2, 421-430.

DePonte, D. P., Weierstall, U., Schmidt, K., Warner, J., Starodub, D., Spence, J. C. H. \& Doak, R. B. (2008). J. Phys. D Appl. Phys. 41, 195505.

Fenalti, G., Zatsepin, N. A., Betti, C., Giguere, P., Han, G. W., Ishchenko, A., Liu, W., Guillemyn, K., Zhang, H., James, D., Wang, D., Weierstall, U., Spence, J. C. H., Boutet, S., Messerschmidt, M., Williams, G. J., Gati, C., Yefanov, O. M., White, T. A., Oberthuer, D., Metz, M., Yoon, C. H., Barty, A., Chapman, H. N., Basu, S., Coe, J., Conrad, C. E., Fromme, R., Fromme, P., Tourwé, D., Schiller, P. W., Roth, B. L., Ballet, S., Katritch, V., Stevens, R. C. \& Cherezov, V. (2015). Nat. Struct. Mol. Biol. 22, 265-268.

Fukuda, Y., Tse, K. M., Suzuki, M., Diederichs, K., Hirata, K., Nakane, T., Sugahara, M., Nango, E., Tono, K., Joti, Y., Kameshima, T., Song, C., Hatsui, T., Yabashi, M., Nureki, O., Matsumura, H., Inoue, T., Iwata, S. \& Mizohata, E. (2016). J. Biochem. 159, 527-538.

Gevorkov, Y., Yefanov, O., Barty, A., White, T. A., Mariani, V., Brehm, W., Tolstikova, A., Grigat, R.-R. \& Chapman, H. N. (2019). Acta Cryst. A75, 694-704.

Hasegawa, K., Shimizu, N., Okumura, H., Mizuno, N., Baba, S., Hirata, K., Takeuchi, T., Yamazaki, H., Senba, Y., Ohashi, H., Yamamoto, M. \& Kumasaka, T. (2013). J. Synchrotron Rad. 20, 910-913.

Hirata, K., Shinzawa-Itoh, K., Yano, N., Takemura, S., Kato, K., Hatanaka, M., Muramoto, K., Kawahara, T., Tsukihara, T., Yamashita, E., Tono, K., Ueno, G., Hikima, T., Murakami, H., Inubushi, Y., Yabashi, M., Ishikawa, T., Yamamoto, M., Ogura, T., Sugimoto, H., Shen, J. R., Yoshikawa, S. \& Ago, H. (2014). Nat. Methods, 11, 734-736.

Ishchenko, A., Wacker, D., Kapoor, M., Zhang, A., Han, G. W., Basu, S., Patel, N., Messerschmidt, M., Weierstall, U., Liu, W., Katritch, V.,
Roth, B. L., Stevens, R. C. \& Cherezov, V. (2017). Proc. Natl Acad. Sci. USA, 114, 8223-8228.

Ishikawa, T., Aoyagi, H., Asaka, T., Asano, Y., Azumi, N., Bizen, T., Ego, H., Fukami, K., Fukui, T., Furukawa, Y., Goto, S., Hanaki, H., Hara, T., Hasegawa, T., Hatsui, T., Higashiya, A., Hirono, T., Hosoda, N., Ishii, M., Inagaki, T., Inubushi, Y., Itoga, T., Joti, Y., Kago, M., Kameshima, T., Kimura, H., Kirihara, Y., Kiyomichi, A., Kobayashi, T., Kondo, C., Kudo, T., Maesaka, H., Maréchal, X. M., Masuda, T., Matsubara, S., Matsumoto, T., Matsushita, T., Matsui, S., Nagasono, M., Nariyama, N., Ohashi, H., Ohata, T., Ohshima, T., Ono, S., Otake, Y., Saji, C., Sakurai, T., Sato, T., Sawada, K., Seike, T., Shirasawa, K., Sugimoto, T., Suzuki, S., Takahashi, S., Takebe, H., Takeshita, K., Tamasaku, K., Tanaka, H., Tanaka, R., Tanaka, T., Togashi, T., Togawa, K., Tokuhisa, A., Tomizawa, H., Tono, K., Wu, S., Yabashi, M., Yamaga, M., Yamashita, A., Yanagida, K., Zhang, C., Shintake, T., Kitamura, H. \& Kumagai, N. (2012). Nat. Photon. 6, 540-544.

Jin, M. S., Oldham, M. L., Zhang, Q. \& Chen, J. (2012). Nature, 490, 566-569.

Johansson, L. C., Arnlund, D., Katona, G., White, T. A., Barty, A., Deponte, D. P., Shoeman, R. L., Wickstrand, C., Sharma, A., Williams, G. J., Aquila, A., Bogan, M. J., Caleman, C., Davidsson, J., Doak, R. B., Frank, M., Fromme, R., Galli, L., Grotjohann, I., Hunter, M. S., Kassemeyer, S., Kirian, R. A., Kupitz, C., Liang, M., Lomb, L., Malmerberg, E., Martin, A. V., Messerschmidt, M., Nass, K., Redecke, L., Seibert, M. M., Sjöhamn, J., Steinbrener, J., Stellato, F., Wang, D., Wahlgren, W. Y., Weierstall, U., Westenhoff, S., Zatsepin, N. A., Boutet, S., Spence, J. C. H., Schlichting, I., Chapman, H. N., Fromme, P. \& Neutze, R. (2013). Nat. Commun. 4, 2911.

Johansson, L. C., Stauch, B., Ishchenko, A. \& Cherezov, V. (2017). Trends Biochem. Sci. 42, 749-762.

Johansson, L. C., Stauch, B., McCorvy, J. D., Han, G. W., Patel, N., Huang, X. P., Batyuk, A., Gati, C., Slocum, S. T., Li, C., Grandner, J. M., Hao, S., Olsen, R. H. J., Tribo, A. R., Zaare, S., Zhu, L., Zatsepin, N. A., Weierstall, U., Yous, S., Stevens, R. C., Liu, W., Roth, B. L., Katritch, V. \& Cherezov, V. (2019). Nature, 569, 289-292.

Johnson, Z. L. \& Chen, J. (2017). Cell, 168, 1075-1085.e9.

Johnson, Z. L. \& Chen, J. (2018). Cell, 172, 81-89.e10.

Kabsch, W. (2010). Acta Cryst. D66, 125-132.

Kameshima, T., Ono, S., Kudo, T., Ozaki, K., Kirihara, Y., Kobayashi, K., Inubushi, Y., Yabashi, M., Horigome, T., Holland, A., Holland, K., Burt, D., Murao, H. \& Hatsui, T. (2014). Rev. Sci. Instrum. 85, 033110 .

Kang, Y., Zhou, X. E., Gao, X., He, Y., Liu, W., Ishchenko, A., Barty, A., White, T. A., Yefanov, O., Han, G. W., Xu, Q., de Waal, P. W., Ke, J., Tan, M. H. E., Zhang, C., Moeller, A., West, G. M., Pascal, B. D., Van Eps, N., Caro, L. N., Vishnivetskiy, S. A., Lee, R. J., SuinoPowell, K. M., Gu, X., Pal, K., Ma, J., Zhi, X., Boutet, S., Williams, G. J., Messerschmidt, M., Gati, C., Zatsepin, N. A., Wang, D., James, D., Basu, S., Roy-Chowdhury, S., Conrad, C. E., Coe, J., Liu, H., Lisova, S., Kupitz, C., Grotjohann, I., Fromme, R., Jiang, Y., Tan, M., Yang, H., Li, J., Wang, M., Zheng, Z., Li, D., Howe, N., Zhao, Y., Standfuss, J., Diederichs, K., Dong, Y., Potter, C. S., Carragher, B., Caffrey, M., Jiang, H., Chapman, H. N., Spence, J. C. H., Fromme, P., Weierstall, U., Ernst, O. P., Katritch, V., Gurevich, V. V., Griffin, P. R., Hubbell, W. L., Stevens, R. C., Cherezov, V., Melcher, K. \& Xu, H. E. (2015). Nature, 523, 561-567.

Kern, J., Alonso-Mori, R., Hellmich, J., Tran, R., Hattne, J., Laksmono, H., Glöckner, C., Echols, N., Sierra, R. G., Sellberg, J., Lassalle-Kaiser, B., Gildea, R. J., Glatzel, P., Grosse-Kunstleve, R. W., Latimer, M. J., McQueen, T. A., DiFiore, D., Fry, A. R., Messerschmidt, M., Miahnahri, A., Schafer, D. W., Seibert, M. M., Sokaras, D., Weng, T. C., Zwart, P. H., White, W. E., Adams, P. D., Bogan, M. J., Boutet, S., Williams, G. J., Messinger, J., Sauter, N. K., Zouni, A., Bergmann, U., Yano, J. \& Yachandra, V. K. (2012). Proc. Natl Acad. Sci. USA, 109, 9721-9726. 
Kim, Y. \& Chen, J. (2018). Science, 359, 915-919.

Kodan, A., Yamaguchi, T., Nakatsu, T., Matsuoka, K., Kimura, Y., Ueda, K. \& Kato, H. (2019). Nat. Commun. 10, 88.

Kodan, A., Yamaguchi, T., Nakatsu, T., Sakiyama, K., Hipolito, C. J., Fujioka, A., Hirokane, R., Ikeguchi, K., Watanabe, B., Hiratake, J., Kimura, Y., Suga, H., Ueda, K. \& Kato, H. (2014). Proc. Natl Acad. Sci. USA, 111, 4049-4054.

Kovácsová, G., Grünbein, M. L., Kloos, M., Barends, T. R. M., Schlesinger, R., Heberle, J., Kabsch, W., Shoeman, R. L., Doak, R. B. \& Schlichting, I. (2017). IUCrJ, 4, 400-410.

Kovalevskiy, O., Nicholls, R. A., Long, F., Carlon, A. \& Murshudov, G. N. (2018). Acta Cryst. D74, 215-227.

Li, D., Stansfeld, P. J., Sansom, M. S. P., Keogh, A., Vogeley, L., Howe, N., Lyons, J. A., Aragao, D., Fromme, P., Fromme, R., Basu, S., Grotjohann, I., Kupitz, C., Rendek, K., Weierstall, U., Zatsepin, N. A., Cherezov, V., Liu, W., Bandaru, S., English, N. J., Gati, C., Barty, A., Yefanov, O., Chapman, H. N., Diederichs, K., Messerschmidt, M., Boutet, S., Williams, G. J., Seibert, M. M. \& Caffrey, M. (2015). Nat. Commun. 6, 10140.

Liu, W., Wacker, D., Gati, C., Han, G. W., James, D., Wang, D., Nelson, G., Weierstall, U., Katritch, V., Barty, A., Zatsepin, N. A., Li, D., Messerschmidt, M., Boutet, S., Williams, G. J., Koglin, J. E., Seibert, M. M., Wang, C., Shah, S. T. A., Basu, S., Fromme, R., Kupitz, C., Rendek, K. N., Grotjohann, I., Fromme, P., Kirian, R. A., Beyerlein, K. R., White, T. A., Chapman, H. N., Caffrey, M., Spence, J. C. H., Stevens, R. C. \& Cherezov, V. (2013). Science, 342, 1521-1524.

Manolaridis, I., Jackson, S. M., Taylor, N. M. I., Kowal, J., Stahlberg, H. \& Locher, K. P. (2018). Nature, 563, 426-430.

Martiel, I., Müller-Werkmeister, H. M. \& Cohen, A. E. (2019). Acta Cryst. D75, 160-177.

Martin-Garcia, J. M., Conrad, C. E., Nelson, G., Stander, N., Zatsepin, N. A., Zook, J., Zhu, L., Geiger, J., Chun, E., Kissick, D., Hilgart, M. C., Ogata, C., Ishchenko, A., Nagaratnam, N., Roy-Chowdhury, S., Coe, J., Subramanian, G., Schaffer, A., James, D., Ketwala, G., Venugopalan, N., Xu, S., Corcoran, S., Ferguson, D., Weierstall, U., Spence, J. C. H., Cherezov, V., Fromme, P., Fischetti, R. F. \& Liu, W. (2017). IUCrJ, 4, 439-454.

McCoy, A. J., Grosse-Kunstleve, R. W., Adams, P. D., Winn, M. D., Storoni, L. C. \& Read, R. J. (2007). J. Appl. Cryst. 40, 658-674.

Misquitta, L. V., Misquitta, Y., Cherezov, V., Slattery, O., Mohan, J. M., Hart, D., Zhalnina, M., Cramer, W. A. \& Caffrey, M. (2004). Structure, 12, 2113-2124.

Mizohata, E., Nakane, T., Fukuda, Y., Nango, E. \& Iwata, S. (2018). Biophys. Rev. 10, 209-218.

Nakane, T., Hanashima, S., Suzuki, M., Saiki, H., Hayashi, T., Kakinouchi, K., Sugiyama, S., Kawatake, S., Matsuoka, S., Matsumori, N., Nango, E., Kobayashi, J., Shimamura, T., Kimura, K., Mori, C., Kunishima, N., Sugahara, M., Takakyu, Y., Inoue, S., Masuda, T., Hosaka, T., Tono, K., Joti, Y., Kameshima, T., Hatsui, T., Yabashi, M., Inoue, T., Nureki, O., Iwata, S., Murata, M. \& Mizohata, E. (2016). Proc. Natl Acad. Sci. USA, 113, 13039-13044.

Nakane, T., Joti, Y., Tono, K., Yabashi, M., Nango, E., Iwata, S., Ishitani, R. \& Nureki, O. (2016). J. Appl. Cryst. 49, 1035-1041.

Nakane, T., Song, C., Suzuki, M., Nango, E., Kobayashi, J., Masuda, T., Inoue, S., Mizohata, E., Nakatsu, T., Tanaka, T., Tanaka, R., Shimamura, T., Tono, K., Joti, Y., Kameshima, T., Hatsui, T., Yabashi, M., Nureki, O., Iwata, S. \& Sugahara, M. (2015). Acta Cryst. D71, 2519-2525.

Nam, K. H. (2019). Int. J. Mol. Sci. 20, 1094.

Nango, E., Royant, A., Kubo, M., Nakane, T., Wickstrand, C., Kimura, T., Tanaka, T., Tono, K., Song, C., Tanaka, R., Arima, T., Yamashita, A., Kobayashi, J., Hosaka, T., Mizohata, E., Nogly, P., Sugahara, M., Nam, D., Nomura, T., Shimamura, T., Im, D., Fujiwara, T., Yamanaka, Y., Jeon, B., Nishizawa, T., Oda, K., Fukuda, M., Andersson, R., Båth, P., Dods, R., Davidsson, J., Matsuoka, S., Kawatake, S., Murata, M., Nureki, O., Owada, S., Kameshima, T., Hatsui, T., Joti, Y., Schertler, G., Yabashi, M., Bondar, A. N., Standfuss, J., Neutze, R. \& Iwata, S. (2016). Science, 354, 1552-1557.
Nass, K., Meinhart, A., Barends, T. R. M., Foucar, L., Gorel, A., Aquila, A., Botha, S., Doak, R. B., Koglin, J., Liang, M., Shoeman, R. L., Williams, G., Boutet, S. \& Schlichting, I. (2016). IUCrJ, 3, 180-191.

Nogly, P., Panneels, V., Nelson, G., Gati, C., Kimura, T., Milne, C., Milathianaki, D., Kubo, M., Wu, W., Conrad, C., Coe, J., Bean, R., Zhao, Y., Båth, P., Dods, R., Harimoorthy, R., Beyerlein, K. R., Rheinberger, J., James, D., DePonte, D., Li, C., Sala, L., Williams, G. J., Hunter, M. S., Koglin, J. E., Berntsen, P., Nango, E., Iwata, S., Chapman, H. N., Fromme, P., Frank, M., Abela, R., Boutet, S., Barty, A., White, T. A., Weierstall, U., Spence, J., Neutze, R., Schertler, G. \& Standfuss, J. (2016). Nat. Commun. 7, 12314.

Nogly, P., Weinert, T., James, D., Carbajo, S., Ozerov, D., Furrer, A., Gashi, D., Borin, V., Skopintsev, P., Jaeger, K., Nass, K., Båth, P., Bosman, R., Koglin, J., Seaberg, M., Lane, T., Kekilli, D., Brünle, S., Tanaka, T., Wu, W., Milne, C., White, T., Barty, A., Weierstall, U., Panneels, V., Nango, E., Iwata, S., Hunter, M., Schapiro, I., Schertler, G., Neutze, R. \& Standfuss, J. (2018). Science, 361, eaat0094.

Pande, K., Hutchison, C. D. M., Groenhof, G., Aquila, A., Robinson, J. S., Tenboer, J., Basu, S., Boutet, S., DePonte, D. P., Liang, M., White, T. A., Zatsepin, N. A., Yefanov, O., Morozov, D., Oberthuer, D., Gati, C., Subramanian, G., James, D., Zhao, Y., Koralek, J., Brayshaw, J., Kupitz, C., Conrad, C., Roy-Chowdhury, S., Coe, J. D., Metz, M., Xavier, P. L., Grant, T. D., Koglin, J. E., Ketawala, G., Fromme, R., Šrajer, V., Henning, R., Spence, J. C., Ourmazd, A., Schwander, P., Weierstall, U., Frank, M., Fromme, P., Barty, A., Chapman, H. N., Moffat, K., van Thor, J. J. \& Schmidt, M. (2016). Science, 352, 725-729.

Park, J., Park, S., Kim, J., Park, G., Cho, Y. \& Nam, K. H. (2019). Sci. Rep. 9, 2525.

Rasmussen, S. G. F., DeVree, B. T., Zou, Y., Kruse, A. C., Chung, K. Y., Kobilka, T. S., Thian, F. S., Chae, P. S., Pardon, E., Calinski, D., Mathiesen, J. M., Shah, S. T. A., Lyons, J. A., Caffrey, M., Gellman, S. H., Steyaert, J., Skiniotis, G., Weis, W. I., Sunahara, R. K. \& Kobilka, B. K. (2011). Nature, 477, 549-555.

Rees, D. C., Johnson, E. \& Lewinson, O. (2009). Nat. Rev. Mol. Cell Biol. 10, 218-227.

Robey, R. W., Pluchino, K. M., Hall, M. D., Fojo, A. T., Bates, S. E. \& Gottesman, M. M. (2018). Nat. Rev. Cancer, 18, 452-464.

Shimada, A., Kubo, M., Baba, S., Yamashita, K., Hirata, K., Ueno, G., Nomura, T., Kimura, T., Shinzawa-Itoh, K., Baba, J., Hatano, K., Eto, Y., Miyamoto, A., Murakami, H., Kumasaka, T., Owada, S., Tono, K., Yabashi, M., Yamaguchi, Y., Yanagisawa, S., Sakaguchi, M., Ogura, T., Komiya, R., Yan, J., Yamashita, E., Yamamoto, M., Ago, H., Yoshikawa, S. \& Tsukihara, T. (2017). Sci. Adv. 3, e1603042.

Shimazu, Y., Tono, K., Tanaka, T., Yamanaka, Y., Nakane, T., Mori, C., Terakado Kimura, K., Fujiwara, T., Sugahara, M., Tanaka, R., Doak, R. B., Shimamura, T., Iwata, S., Nango, E. \& Yabashi, M. (2019). J. Appl. Cryst. 52, 1280-1288.

Spence, J. C. H. (2017). IUCrJ, 4, 322-339.

Srikant, S. \& Gaudet, R. (2019). Nat. Struct. Mol. Biol. 26, 792-801.

Stagno, J. R., Liu, Y., Bhandari, Y. R., Conrad, C. E., Panja, S., Swain, M., Fan, L., Nelson, G., Li, C., Wendel, D. R., White, T. A., Coe, J. D., Wiedorn, M. O., Knoska, J., Oberthuer, D., Tuckey, R. A., Yu, P., Dyba, M., Tarasov, S. G., Weierstall, U., Grant, T. D., Schwieters, C. D., Zhang, J., Ferré-D'Amaré, A. R., Fromme, P., Draper, D. E., Liang, M., Hunter, M. S., Boutet, S., Tan, K., Zuo, X., Ji, X., Barty, A., Zatsepin, N. A., Chapman, H. N., Spence, J. C. H., Woodson, S. A. \& Wang, Y. X. (2017). Nature, 541, 242-246.

Suga, M., Akita, F., Hirata, K., Ueno, G., Murakami, H., Nakajima, Y., Shimizu, T., Yamashita, K., Yamamoto, M., Ago, H. \& Shen, J. R. (2015). Nature, 517, 99-103.

Suga, M., Akita, F., Sugahara, M., Kubo, M., Nakajima, Y., Nakane, T., Yamashita, K., Umena, Y., Nakabayashi, M., Yamane, T., Nakano, T., Suzuki, M., Masuda, T., Inoue, S., Kimura, T., Nomura, T., Yonekura, S., Yu, L. J., Sakamoto, T., Motomura, T., Chen, J. H., 
Kato, Y., Noguchi, T., Tono, K., Joti, Y., Kameshima, T., Hatsui, T., Nango, E., Tanaka, R., Naitow, H., Matsuura, Y., Yamashita, A., Yamamoto, M., Nureki, O., Yabashi, M., Ishikawa, T., Iwata, S. \& Shen, J. R. (2017). Nature, 543, 131-135.

Sugahara, M., Mizohata, E., Nango, E., Suzuki, M., Tanaka, T., Masuda, T., Tanaka, R., Shimamura, T., Tanaka, Y., Suno, C., Ihara, K., Pan, D., Kakinouchi, K., Sugiyama, S., Murata, M., Inoue, T., Tono, K., Song, C., Park, J., Kameshima, T., Hatsui, T., Joti, Y., Yabashi, M. \& Iwata, S. (2015). Nat. Methods, 12, 61-63.

Sugahara, M., Nakane, T., Masuda, T., Suzuki, M., Inoue, S., Song, C., Tanaka, R., Nakatsu, T., Mizohata, E., Yumoto, F., Tono, K., Joti, Y., Kameshima, T., Hatsui, T., Yabashi, M., Nureki, O., Numata, K., Nango, E. \& Iwata, S. (2017). Sci. Rep. 7, 703.

Sugahara, M., Song, C., Suzuki, M., Masuda, T., Inoue, S., Nakane, T., Yumoto, F., Nango, E., Tanaka, R., Tono, K., Joti, Y., Kameshima, T., Hatsui, T., Yabashi, M., Nureki, O., Numata, K. \& Iwata, S. (2016). Sci. Rep. 6, 4-9.

Taylor, N. M. I., Manolaridis, I., Jackson, S. M., Kowal, J., Stahlberg, H. \& Locher, K. P. (2017). Nature, 546, 504-509.

Tenboer, J., Basu, S., Zatsepin, N., Pande, K., Milathianaki, D., Frank, M., Hunter, M., Boutet, S., Williams, G. J., Koglin, J. E., Oberthuer, D., Heymann, M., Kupitz, C., Conrad, C., Coe, J., Roy-Chowdhury, S., Weierstall, U., James, D., Wang, D., Grant, T., Barty, A., Yefanov, O., Scales, J., Gati, C., Seuring, C., Srajer, V., Henning, R., Schwander, P., Fromme, R., Ourmazd, A., Moffat, K., Van Thor, J. J., Spence, J. C. H., Fromme, P., Chapman, H. N. \& Schmidt, M. (2014). Science, 346, 1242-1246.

Thomas, C. \& Tampé, R. (2020). Annu. Rev. Biochem. 89, 605-636.

Tono, K., Nango, E., Sugahara, M., Song, C., Park, J., Tanaka, T., Tanaka, R., Joti, Y., Kameshima, T., Ono, S., Hatsui, T., Mizohata, E., Suzuki, M., Shimamura, T., Tanaka, Y., Iwata, S. \& Yabashi, M. (2015). J. Synchrotron Rad. 22, 532-537.

Tono, K., Togashi, T., Inubushi, Y., Sato, T., Katayama, T., Ogawa, K., Ohashi, H., Kimura, H., Takahashi, S., Takeshita, K., Tomizawa, H., Goto, S., Ishikawa, T. \& Yabashi, M. (2013). New J. Phys. 15, 083035 .

Tosha, T., Nomura, T., Nishida, T., Saeki, N., Okubayashi, K., Yamagiwa, R., Sugahara, M., Nakane, T., Yamashita, K., Hirata, K., Ueno, G., Kimura, T., Hisano, T., Muramoto, K., Sawai, H., Takeda, H., Mizohata, E., Yamashita, A., Kanematsu, Y., Takano, Y., Nango, E., Tanaka, R., Nureki, O., Shoji, O., Ikemoto, Y., Murakami, H., Owada, S., Tono, K., Yabashi, M., Yamamoto, M., Ago, H., Iwata, S., Sugimoto, H., Shiro, Y. \& Kubo, M. (2017). Nat. Commun. 8, 1585.

Ward, A. B., Szewczyk, P., Grimard, V., Lee, C. W., Martinez, L., Doshi, R., Caya, A., Villaluz, M., Pardon, E., Cregger, C., Swartz,
D. J., Falson, P. G., Urbatsch, I. L., Govaerts, C., Steyaert, J. \& Chang, G. (2013). Proc. Natl Acad. Sci. USA, 110, 13386-13391.

Weierstall, U., James, D., Wang, C., White, T. A., Wang, D., Liu, W., Spence, J. C. H., Bruce Doak, R., Nelson, G., Fromme, P., Fromme, R., Grotjohann, I., Kupitz, C., Zatsepin, N. A., Liu, H., Basu, S., Wacker, D., Won Han, G., Katritch, V., Boutet, S., Messerschmidt, M., Williams, G. J., Koglin, J. E., Marvin Seibert, M., Klinker, M., Gati, C., Shoeman, R. L., Barty, A., Chapman, H. N., Kirian, R. A., Beyerlein, K. R., Stevens, R. C., Li, D., Shah, S. T. A., Howe, N., Caffrey, M. \& Cherezov, V. (2014). Nat. Commun. 5, 3309.

White, T. A., Kirian, R. A., Martin, A. V., Aquila, A., Nass, K., Barty, A. \& Chapman, H. N. (2012). J. Appl. Cryst. 45, 335-341.

Yamashita, K., Kuwabara, N., Nakane, T., Murai, T., Mizohata, E., Sugahara, M., Pan, D., Masuda, T., Suzuki, M., Sato, T., Kodan, A., Yamaguchi, T., Nango, E., Tanaka, T., Tono, K., Joti, Y., Kameshima, T., Hatsui, T., Yabashi, M., Manya, H., Endo, T., Kato, R., Senda, T., Kato, H., Iwata, S., Ago, H., Yamamoto, M., Yumoto, F. \& Nakatsu, T. (2017). IUCrJ, 4, 639-647.

Yamashita, K., Pan, D., Okuda, T., Sugahara, M., Kodan, A., Yamaguchi, T., Murai, T., Gomi, K., Kajiyama, N., Mizohata, E., Suzuki, M., Nango, E., Tono, K., Joti, Y., Kameshima, T., Park, J., Song, C., Hatsui, T., Yabashi, M., Iwata, S., Kato, H., Ago, H., Yamamoto, M. \& Nakatsu, T. (2015). Sci. Rep. 5, 14017.

Zeldin, O. B., Gerstel, M. \& Garman, E. F. (2013). J. Appl. Cryst. 46, 1225-1230.

Zhang, H., Han, G. W., Batyuk, A., Ishchenko, A., White, K. L., Patel, N., Sadybekov, A., Zamlynny, B., Rudd, M. T., Hollenstein, K., Tolstikova, A., White, T. A., Hunter, M. S., Weierstall, U., Liu, W., Babaoglu, K., Moore, E. L., Katz, R. D., Shipman, J. M., GarciaCalvo, M., Sharma, S., Sheth, P., Soisson, S. M., Stevens, R. C., Katritch, V. \& Cherezov, V. (2017). Nature, 544, 327-332.

Zhang, H., Qiao, A., Yang, D., Yang, L., Dai, A., de Graaf, C., ReedtzRunge, S., Dharmarajan, V., Zhang, H., Han, G. W., Grant, T. D., Sierra, R. G., Weierstall, U., Nelson, G., Liu, W., Wu, Y., Ma, L., Cai, X., Lin, G., Wu, X., Geng, Z., Dong, Y., Song, G., Griffin, P. R., Lau, J., Cherezov, V., Yang, H., Hanson, M. A., Stevens, R. C., Zhao, Q., Jiang, H., Wang, M. W. \& Wu, B. (2017). Nature, 546, 259-264.

Zhang, H., Unal, H., Gati, C., Han, G. W., Liu, W., Zatsepin, N. A., James, D., Wang, D., Nelson, G., Weierstall, U., Sawaya, M. R., Xu, Q., Messerschmidt, M., Williams, G. J., Boutet, S., Yefanov, O. M., White, T. A., Wang, C., Ishchenko, A., Tirupula, K. C., Desnoyer, R., Coe, J., Conrad, C. E., Fromme, P., Stevens, R. C., Katritch, V., Karnik, S. S. \& Cherezov, V. (2015). Cell, 161, 833-844.

Zhang, X., Zhao, F., Wu, Y., Yang, J., Han, G. W., Zhao, S., Ishchenko, A., Ye, L., Lin, X., Ding, K., Dharmarajan, V., Griffin, P. R., Gati, C., Nelson, G., Hunter, M. S., Hanson, M. A., Cherezov, V., Stevens, R. C., Tan, W., Tao, H. \& Xu, F. (2017). Nat. Commun. 8, 15383. 